\title{
EKSTRAKSI FLAVONOID DARI DAUN KERSEN (Muntinga calabura L) MENGGUNAKAN PELARUT ETANOL DENGAN METODE MAE (Microwave Assisted Extraction) DAN UAE(Ultrasonic Assisted Extraction)
}

\author{
Siti Indana Isdiyanti", Laeli Kurniasari, Farikha Maharani \\ Jurusan Teknik Kimia, Fakultas Teknik, Universitas Wahid Hasyim Semarang \\ Jl. Menoreh Tengah X/22, Sampangan, Semarang 50236 \\ "Email : indanaisdiyanti16 @ gmail.com
}

\begin{abstract}
Abstrak
Kersen (Muntinga calabura L) adalah pohon yang memiliki buah kecil dan manis. Tumbuhan ini dimanfaatkan antara lain sebagai obat penurun panas, mengobati pembengkakan kelenjar prostat dan mengobati penyakit asam urat, selain itu juga dapat dimanfaatkan sebagai antiseptic, antioksidan, antimikroba, dan anti inflamasi. Berbagai macam metode ekstraksi telah dikembangkan dari yang konvensional ke metode modern, dimana salah satunya yaitu Microwave Assisted Extraction (MAE) dan Ultrasound Assisted Extraction (UAE). Penelitian ini bertujuan untuk menganalisa pengaruh metode ekstraksi yang dilakukan terhadap rendemen,menganalisa pengaruh rasio solid berbanding liquid serta waktu terhadap rendemen, dan menguji kadar flavonoid yang dihasilkan dari kedua metode tersebut. Percobaan dilakukan dengan variabel rasio-pelarut 1:5 - 1:25, sedangkan variabel waktu 5 menit - 25 menit. Hasil percobaan menunjukan bahwa ke dua variabel berpengaruh terhadap konsentrasi flavonoid hasil ekstraksi. Secara umum meningkat seiring kenaikan variabel sampai maksimum di titik tertentu, kemudian turun. Konsentrasi maksimum diperoleh pada variabel umpan-pelarut MAE sebesar 1:25 dengan kadar flavonoid 132,41 mg/ml dan rendemen sebesar 39\%. Adapun waktu terbaik adalah 5 menit dengan kadar flavonoid 91,669 $\mathrm{mg} / \mathrm{ml}$ dan rendemensebesar 22,7\%. Sedangkan pada proses UAE (Ultrasonic Assisted Extraction) dengan rasio umpan-pelarut maksimal sebesar 1:10 dengan kadar flavonoid 47,5899 $\mathrm{mg} / \mathrm{ml}$ dan rendemen $26 \%$. Sedangkan waktu terbaik 10 menit dengan kadar flavonoid 56,7769 $\mathrm{mg} / \mathrm{ml}$ dan rendemen sebesar 19,65\%.
\end{abstract}

\begin{abstract}
Abstrac
Kersen (Muntinga calabura L) is a tree with small and sweet fruit. The fruit is used, among others, as a febrifuge, treating swelling of the prostate gland and treating gout. Besides the fruit, its leaves also has potential as an antiseptic, antioxidant, antimicrobial, and antiinflammatory. Various extraction methods have been developed from conventional to modern methods, one of which is Microwave Assisted Extraction (MAE) and Ultrasound Assisted Extraction (UAE). The research will extract the kersen leaves and aim to analyze the effect of the extraction method on the yield, the effect of the solid to liquid ratio and time on the yield, and the flavonoid content produced by both methods. The experiment was carried out with a solvent-ratio variable of 1:5 - 1:25, while the time variable was $5-25$ minutes. The results of the experiment showed that the two variables had an effect on the concentration of flavonoids extracted. In general, it increases as the variables increase to a maximum point, then decreases. The maximum concentration obtained in the feed-solvent variable MAE was 1:25 with a flavonoid content of $132.41 \mathrm{mg} / \mathrm{ml}$, with a yield of $39 \%$ and the best time was 5 minutes with a flavonoid content of $91.669 \mathrm{mg} / \mathrm{ml}$, with a yield of 22.7\%. While in the UAE Ultrasonic Assisted Extraction process with a maximum feedsolvent ratio of 1:10 with a flavonoid content $47.5899 \mathrm{mg} / \mathrm{ml}$ and yield $26 \%$, while the best time of process was 10 minutes with flavonoid content $56.7769 \mathrm{mg} / \mathrm{ml}$ and yield $19,65 \%$.
\end{abstract}

Kata kunci: Flavonoid, Ekstrak Kersen, MAE, UA

\section{PENDAHULUAN}

Indonesia adalah negara yang kaya akan keanekaragaman tumbuhan yang dapat dimanfaatkan dalam semua segi kehidupan manusia. Obat tradisional adalah salah satu bentuk nyata pemanfaatan tumbuhan yang ada di Indonesia. Tumbuhan ini dimanfaatkan antara lain sebagai obat penurun panas, mengobati pembengkakan kelenjar prostat dan mengobati penyakit asam urat selain itu juga dapat dimanfaatkan sebagai antiseptik, antioksidan, antimikroba dan anti inflamasi. Salah satu tanaman yang dapat dimanfaatkan 
sebagai tanaman obat adalah daun kersen (Muntingia calabura).

Kegunaan tumbuhan kersen sebagai obat tradisional tidak lepas dari keberadaan senyawa-senyawa kimia yang terkandung didalamnya. Senyawa golongan flavonoid merupakan salah satu senyawa yang terkandung didalamnya. Tumbuhan yang mengandung senyawa metabolit sekunder berupa flavonoid dan fenol berguna sebagai penangkap radikal bebas, yang memiliki aktivitas sebagai antioksidan (Nishantini,dkk., 2012).

Flavonoid dalam daun kersen memiliki potensi sebagai antioksidan, hepatoprotektor, analgestik, anti inflamasi, anti kanker, dan antiplatelet. Daun kersen mengandung senyawa flavonoid, saponin, polifenol dan tanin sehingga dapat digunakan sebagai antioksidan (Mintowati dkk 2013). Chen,dkk (2007) dan Zakaria,dkk (2011) melaporkan bahwa kersen mengandung flavonoid yang mempunyai khasiat hipotensi, antinosiseptik, antioksidan, antiproliferatif dan antimikroba melalui isolasi staphylococcus.

Beberapa penelitian tentang ekstraksi flavonoid dari berbagai tumbuhan telah dilakukan. Berdasarkan penelitian Farah, (2008) kandungan flavonoid pada daun jati belanda dapat diekstraksi dengan pelarut etanol dan kadar terbaik flavonoid diperoleh pada variabel perbandingan berat bahan baku dengan volume etanol 1:10 dan konsentrasi etanol 70\%.

Berbagai macam metode ekstraksi telah dikembangkan dari yang konvensional ke metode modern, dimana salah satunya yaitu Microwave Assisted Extraction (MAE) dan Ultrasound Assisted Extraction (UAE). Penelitian ini bertujuan untuk menganalisa pengaruh metode ekstraksi yang dilakukan terhadap rendemen, menganalisa pengaruh rasio solid berbanding liquid serta waktu terhadap rendemen, dan menguji kadar flavonoid yang dihasilkan dari kedua metode tersebut.

\section{METODOLOGI Peralatan}

MAE, Spectrofotometri UV-VIS, Ultrasonic ayakan 40mesh, gelas beker, gelas ukur, labu alas bulat, labu ukur, Erlenmeyer, timbangan, kertas saring, dan corong saring, Sonicator, penangas air,rotary evaporator.

Bahan Penelitian

Bubuk daun Kersen, pelarut etanol 70\%, aquadest, ekstrak daun kersen, kalium asetat $1 \mathrm{M}$, alumunium klorida, quercetin.

\section{PROSEDUR PERCOBAAN \\ Persiapan Bahan}

Pengambilan daun kersen yang berasal dari Kecamatan Cepiring, Kabupaten Kendal. Daun kersen kemudian disortir dan dicuci bersih, setelah itu diagin-anginkan selama 24 jam dengan suhu ruang dan tidak terpapar sinar matahari secara langsung. Kemudian di keringkan menggunakan TryDyer. Daun kersen yang sudah keringkemudin diblender, setelah itu diayakmenggunakan ayakan 40 mesh hingga mendapatkan serbuk simplisia daun kersen.

\section{Proses Ekstraksi}

- Metode $M A E$

Simplisia daun kersen di ekstrak dengan pelarut Etanol 70\% dengan perbandingan rasio $1: 5, \quad 1: 10, \quad 1: 15, \quad 1: 20, \quad 1: 25$ dibantu menggunakan MAE dengan daya $50 \%$ serta dengan waktu ekstraksi 5, 10, 15, 20, 25menit.

\section{- Metode $U A E$}

Simplisia daun kersen dengan pelarut etanol $70 \%$ dengan perbandingan rasio 1:5 1:10, 1:15, 1:20, 1:25 kemudian diekstraksi dengan ultrasonic bath frekuensi $40 \mathrm{kHz}$ selama 5, 10, 15, 20, 25 menit. Hasil ekstraksi diuapkan menggunakan rotary evaporator dengan suhu $40^{\circ} \mathrm{C}$ dan kecepatan $100 \mathrm{rpm}$ hingga diperoleh ekstrak etanolik daun kersen.

\section{Membuat Larutan Standar Baku}

Larutan induk kuersetin (larutan standar) ditimbang 0,001 gr kuersetin. Kemudian dilarutkan di dalam labu ukur $100 \mathrm{ml}$ menggunakan aquadest. Sehingga didapatkan konsentrasi sebesar $10 \mathrm{ppm}$.

\section{Analisa Flavonoid}

Sebanyak 0,5 ml ekstrak daun kersen kemudian tambahkan $0,1 \mathrm{ml}$ Alumunium Klorida 10\%. 0,1 ml Kalium Asetat $1 \mathrm{M}$ dan Etanol 4,3 ml. Diamkan larutan tersebut selama 40 menit. Selanjutnya analisa menggunakan Spektrofotometri UV-Vis dengan panjang gelombang $365 \mathrm{~nm}$.

\section{HASIL DAN PEMBAHASAN \\ Pengaruh Rasio Umpan-Pelarut \\ - Metode MAE}

Pengaruh variabel rasio umpan-pelarut dievaluasi melalui percobaan dengan variabel rasio umpan-pelarut sebesar 1:5, 1:10, 1:15, 1:20, dan $1: 25 \mathrm{~b} / \mathrm{v}$, pada daya sebesar $50 \%$ dari daya maksimum (399 watt) dan waktu 
ekstraksi selama 15 menit. Perhitungan rendemen dan analisa konsentrasi flavonoid yang diperoleh tersaji pada tabel 1 .

Tabel 2. Rasio Umpan-Pelarut pada Metode UAE (Ultrasound Assisted Extraction).

\begin{tabular}{|c|c|c|c|}
\hline $\begin{array}{c}\text { Umpan: } \\
\text { Pelarut } \\
\text { (b/v ) }\end{array}$ & $\begin{array}{c}\text { Absorbansi } \\
\text { ( A ) }\end{array}$ & $\begin{array}{c}\text { Kadar } \\
\text { Flavonoid } \\
\text { ( mg/ml ) }\end{array}$ & $\begin{array}{c}\text { Rendemen } \\
\text { ( \% ) }\end{array}$ \\
\hline $1: 5$ & 0,7406 & 19,1726 & $5,32 \%$ \\
$1: 10$ & 1,1356 & 47,5899 & $26,89 \%$ \\
$1: 15$ & 0,7286 & 18,3093 & $30,92 \%$ \\
$1: 20$ & 0,562 & 6,3237 & $26,99 \%$ \\
$1: 25$ & 0,6496 & 12,6258 & $37,94 \%$ \\
\hline
\end{tabular}

Rasio umpan-pelarut berpengaruh terhadap hasil ekstraksi flavonoid. Semakin besar jumlah pelarut maka konsentrasi flavonoid juga semakin tinggi, sampai pada titik tertentu. Hasil maksimum diperoleh pada nilai rasio umpan-pelarut $1: 10 \mathrm{~b} / \mathrm{v}$. Nilai rasio umpanpelarut (1:15 dan 1:20) b/v menunjukan bahwa hasil konsentrasi flavonoid yang diperoleh semakin kecil. Hal ini terjadi karena ekstrak sudah berada pada titik jenuh larutan dan intensitas proses kavitasi berkurang oleh karena itu tidak akanterjadi peningkatan hasil ekstraksi dengan penambahan pelarut (Brennan, 2006). Penyebab lain adalah energi dari gelombang ultrasonik diserap terlebih dahulu oleh pelarut sebelum masuk ke dinding sel tanaman di dalam ekstrak sehingga energi gelombang ultrasonik akan berkurang ketika masuk ke dalam dinding sel tanaman (Wang dan Wang, 2004).

\section{Pengaruh Waktu Ekstraksi \\ - Metode MAE}

Evaluasi pengaruh variabel waktu ekstraksi dilakukan pada rentang waktu 5 menit sampai 25 menit, dengan rasio umpan-pelarut dan daya konstan berturut-turut sebesar $1: 25 \mathrm{~b} / \mathrm{v}$ dan daya $50 \%$ daya maksimum (399 watt). Hasil percobaan dapatdilihat pada tabel 3 .

Tabel 3. Pengaruh Waktu Ekstraksi dengan Metode MAE (Microwave AssistedExtraction)

\begin{tabular}{|c|c|c|c|}
\hline $\begin{array}{c}\text { Waktu } \\
\text { ( menit ) }\end{array}$ & $\begin{array}{c}\text { Absorbansi } \\
\text { ( A ) }\end{array}$ & $\begin{array}{c}\text { Kadar } \\
\text { Flavonoid } \\
\text { ( mg/ml ) }\end{array}$ & $\begin{array}{c}\text { Rendemen } \\
\text { ( \% ) }\end{array}$ \\
\hline 5 & 1,7483 & 91,669 & $22,7 \%$ \\
10 & 1,4236 & 68,3093 & $34 \%$ \\
\hline
\end{tabular}

\begin{tabular}{|c|c|c|c|}
15 & 1,242 & 55,2446 & $38,2 \%$ \\
20 & 1,5083 & 74,4028 & $21,8 \%$ \\
25 & 1,225 & 54,0215 & $20,3 \%$ \\
\hline
\end{tabular}

Seiring dengan bertambahnya waktu ekstraksi bahwa konsentrasi flavonoid yang dihasilkan menurun. Pada percobaan ini diperoleh waktu maksimum pada 5 menit dengan konsentrasi flavonoid sebesar 91,669 $\mathrm{mg} / \mathrm{ml}$ untuk ekstraksi lebih dari 5 menit (10 dan 15 menit) diperoleh hasil konsentrasi flavonoid menurun. Ekstraksi dengan bantuan gelombang mikro merupakan prosesyang cepat. Energi akan dipindahkan secara efisien ke dalam bahan melalui interaksi molekuler dibawah medan magnet, menyebabkan perpindahan yang cepat pada pelarut ekstraksi dan bahan tumbuhan. Waktu ekstraksi yang lama akan dapat menyebabkan degredasi flavonoid yang akan menurunkan konsentrasi atau yield percobaan (Huang dkk., 2017 ).

Sedangkan untuk rendemen yangdihasilkan menunjukkan perbedaan yang signifikan. Dilihat dalam tabel 3 bahwa pada waktu 20 dan 25 menit terjadi penurunan rendemen. Hal ini diduga karena penetrasi pelarut etanol ke dalam bahan mengalami penurunan, sehingga komponen yang terambil dalam bahan menjadi sedikit.

Wibowo dan Sudi (2004) dalam Alfiana (2013), menegaskan bahwa lamanya waktu proses ekstraksi sangat berpengaruh terhadap ekstrak yang dihasilkan. Dari tabel diketahui bahwa rendemen ekstrak yang dihasilkan berbeda dalam berbagai perubahan waktu. Kenaikan waktu proses yang digunakan akan menghasilkan kenaikan nilai rendemen, begitu pula lamanya waktu ekstraksi akan meningkatkan penetrasi pelarut ke dalam bahan baku. Kelarutan komponen dalam bahan berjalan dengan perlahan sebanding dengan kenaikan waktu, akan tetapi, setelah mencapai waktu optimal jumlah komponen yang terambil dari bahan akan mengalami penurunan. Hal ini disebabkan komponen- kompoenen yang terdapat dalam bahan jumlahnya terbatas dan pelarut yang digunakan mempunyai batas kemampuan untuk melarutkan bahan yang ada, sehingga walaupun waktu ekstraksi diperpanjang, solute yang ada di dalam bahan sudah tidak ada. 


\section{- Metode UAE}

Evaluasi pengaruh variabel waktu ekstraksi dilakukan pada rentang waktu 5 menit sampai 25 menit, dengan rasio umpan-pelarut dan daya konstan berturut-turut sebesar $1: 10 \mathrm{~b} / \mathrm{v}$ dan frekuensi $45 \mathrm{kHz}$. Hasilpercobaan dapat dilihat pada tabel 4.

Tabel 4. Pengaruh Waktu Ekstraksi dengan Metode UAE (Ultrasound Assisted Extraction)

\begin{tabular}{|c|c|c|c|}
\hline $\begin{array}{c}\text { Waktu } \\
\text { ( menit ) }\end{array}$ & $\begin{array}{c}\text { Absorbansi } \\
\text { ( A ) }\end{array}$ & $\begin{array}{c}\text { Kadar } \\
\text { Flavonoid } \\
\text { ( mg/ml ) }\end{array}$ & $\begin{array}{c}\text { Rendemen } \\
\text { ( \% ) }\end{array}$ \\
\hline 5 & 1,1323 & 47,3525 & $16,02 \%$ \\
10 & 1,2633 & 56,7769 & $19,65 \%$ \\
15 & 1,1667 & 49,8273 & $23,68 \%$ \\
20 & 1,0783 & 43,4676 & $18,09 \%$ \\
25 & 1,1603 & 49,3669 & $25,48 \%$ \\
\hline
\end{tabular}

Hasil analisa tersebut didapatkan bahwa konsentrasi kadar flavonoid maksimum dicapai pada waktu 10 menit dengan jumlah kadar sebesar $56,7769 \mathrm{mg} / \mathrm{ml}$. Sedangkan pada waktu 15, 20,25 menit dengan parameter rata-rata kadar flavonoid menunjukkan perbedaan yang signifikan. Hal ini terjadi karna ekstrak sudah berada pada titik jenuh larutan dan intensitas proses kavitasi berkurang (Brennan, 2006).

Prinsip ekstraksi ini memanfaatkan gelombang ultrasonic yang ditransmisikan melalui pelarut untuk menyebabkan kavitasi mikro pada sekeliling bahan yang akan diekstraksi sehingga terjadi pemanasan akhirnya melepaskan senyawa ekstrak.

Faktor kedua yang mempengaruhi proses ekstraksi adalah lama ekstraksi. Menurut Wahyuni dan Simon (2015), semakin lama waktu ekstraksi maka pelarut memiliki waktu yang lebih banyak untuk menembus dinding sel dan menarik keluar senyawa-senyawa yang terkandung dalam bahan, sehingga dihasilkan rendemen yang lebih tinggi.

\section{KESIMPULAN}

Dari percobaan pada proses MAE Microwave Assisted Extraction dengan rasio umpan-pelarut maksimal sebesar 1;25 diperoleh hasil kadar flavonoid sebesar 132,41 $\mathrm{mg} / \mathrm{ml}$, dengan rendemen sebesar $39 \%$ dan waktu terbaik 5 menit dengan kadar flavonoid $91,669 \mathrm{mg} / \mathrm{ml}$, dengan rendemen sebesar $22,7 \%$.
Sedangkan pada proses UAE Ultrasonic Assisted Extraction dengan rasio umpanpelarut maksimal sebesar 1:10 dengan kadar flavonoid $47,5899 \mathrm{mg} / \mathrm{ml}$, dengan rendemen $26 \%$ dan waktu terbaik 10 menit dengan kadar flavonoid $56,7769 \mathrm{mg} / \mathrm{ml}$, rendemen sebesar $19,65 \%$.

\section{DAFTAR PUSTAKA}

Aulia, L. P., dan Widjanarko, S. B, 2018, Optimasi Proses Ekstraksi Daun Sirsak (Annona Muricata L) Metode MAE (Microwave Assisted Extraction) Dengan Respon Aktivitas Antioksidan dan Total Fenol. Jurnal argoindustri Halal, 4(April),79-87.

Brennan, J.G, 2006, Food Processing Handbook, WILEY-VCH Verlag GmbH7co.KgaA Weinheim,Germany.

Handayani, Hana., Feronika Heppy Sriherfyna, Yunianta. 2016, Ekstraksi Antioksidan Daun Sirsak Metode Ultrasonic Bath (Kajian Rasio Bahan:Pelarut dan Lama Ekstraksi), Jurnal Pangan dan Agroindustri Vol.4 No.1: 262- 272, 2016.

Huang, J., He, W., Yan, C., Du, X., dan Shi, X, (2017), Microwave assisted extraction of flavonoid from pomegranate peel and its antioxidant

activity, BIO Web of Conferences8,03008.

Koirewoa, Y. A., Fatimawali, W.I. Wiyono, 2012, Isolasi dan Identifikasi Senyawa Flavonoid dalam Daun Beluntas (Pluchea Indica $L$ ). Laporan Penelitian FMIPA UNSRAT Manado.

Mc Cullough MJ dan Farah CS,2008, The Role of Alcohol in Oral Carsinogenesis with particular refrence to alcohol containing moutwashes. Australia: Detal Jurnal.

Mintowati, E., Kuntorini, Setya dan Maria, 2013, Struktur Anatomi dan Uji Aktivitas Antioksidan EkstrakMetanol Daun Kersen (Muntingia Calabura), Program Studi BiologiFMIPA, Universtitas Lampung Mangkurat, FMIPA Universitas Lampung. http://jurnal.fmipa.unila.ac.id/index. php/

Veggi PC, Martinez J, Meireles, MAA, 2013, Fundamental of Microwave Extraction : MicrowaveassistedExtraction for Bioactive Compounds: Theory and Practice, Food Engineering Series 4, Springer Science+Business Media New York.

Wahyuni Dyta dan Simon Widjanarko, 2015, Pengaruh Jenis Pelarut dan Lama Ekstraksi 
Karotenoid Labu Kuning dengan metode Gelombang Ultrasonik, Skripsi, FTP, Malang.

Wang, L., dan Wang, Y, 2004, Application of High Intensity Ultrasound and Surfactants in RiceStarch Isolation, Journal Food Science University of Arhansas 81:1, 140144.

Wibowo A, dan Sudi Y. 2004. Ekstraksi Minyak Nilam Dengan Pelarut Normal Heksana. Universitas Diponegoro. Semarang.

Zakaria Z. A., Mohammaed A. M., jamil N.

$\mathrm{S} . \mathrm{M}, 2011$, In vito antiproliferative and antioxidaty activities of the extracts of Muntingia Calabura leaves. The America. Journal of Chinese medicine.39(1).P 183200 